\title{
Una aguja, una lámpara, un telar
}

\author{
Renata Rendelucci Allucci ${ }^{1}$ (iD) 0000-0002-7426-9884 \\ 'Pontifícia Universidade Católica de Campinas, Programa de Pós-Graduação em \\ Arquitetura e Urbanismo, Campinas, SP, Brasil. 13086-900
}

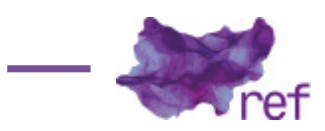

Resumo: O artigo busca compreender alguns aspectos comuns da América Latina, partindo da premissa de que as ditaduras criam identificações entre seus países. A despeito das consequências e dificuldades desse sistema de governo, algumas mulheres latino-americanas encontraram, na prática coletiva do bordado, alternativas para enfrentar e resistir ao poder estabelecido. Em seus trabalhos, elas trazem à luz a história não oficial, denunciando a violação de direitos humanos, expressando seus sentimentos e compartilhando suas experiências. Como exemplos dessas ações, apresentam-se casos de grupos de mulheres da Argentina, Colômbia e Chile, as quais, na tentativa de superar aquilo que as vitimou, transformaram a arte em instrumento de utilização política.

Palavras-chave: América Latina; mulheres; território; bordado.

A needle, a lamp, a loom

Abstract: The article aims to understand some common aspects in Latin America, assuming dictatorships create identifications among their countries. Despite the consequences and difficulties of this governmental system, some Latin American women found alternatives to face and to resist the established power through the practice of collective embroidery. In their pieces, they bring to light the non-official history, denouncing the violation of human rights, expressing their feelings and sharing their experiences. As examples of actions of these groups of women, there are cases from Argentina, Colombia and Chile which, in the attempt to overcome what victimized them, transformed art into a political tool.

Keywords: Latin America; Women; Territory; Embroidery.

\section{Introdução'}

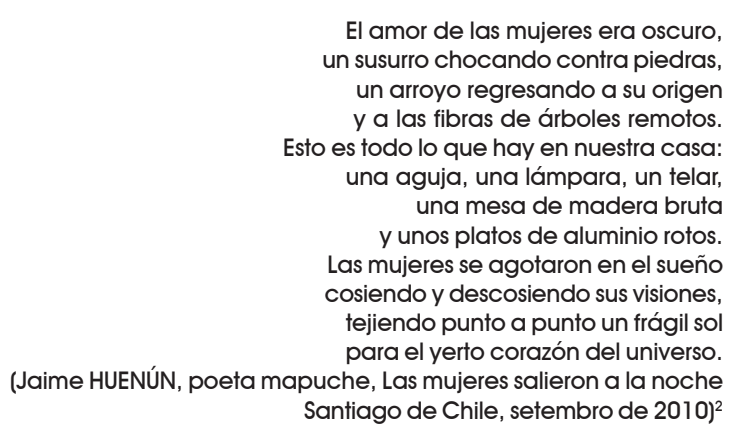

O que é a América Latina? Como se define, quem a define? Por que, no Brasil, a produção dos países vizinhos não faz parte de nossa formação cultural e intelectual? Como chamá-los hermanos se agimos como membros de uma família desgarrada, na qual seus integrantes se olham e veem apenas desconhecidos? Muito a percorrer, muito a modificar.

\footnotetext{
' Agradeço a Cristina Schicchi pela disciplina motivadora desta inspiração, Estudos Urbanos Latino-Americanos. 2Este poema se encontra no catálogo Arpilleras da resistência política chilena. Disponível em: http://cain.ulster.ac.uk/ conflicttextiles/mediafiles/178_2011-07-30_Sao-Paulo_catalogue.pdf
} 
Participando do Seminário Memória, Resistência e Políticas Culturais na América Latina³, ouvi de um palestrante que os desaparecidos, as ditaduras e o extermínio dos indígenas criam identificações entre os países da América Latina. E isso faz pensar, refletir, querer saber. Será que é a dor que nos une? A injustiça, os golpes militares, a violência?

E onde fica a alegria, a música, a cultura, o colorido desses países e povos? Então, uma resposta aparece: a possibilidade de transformação da perda, da dor e dos abusos por meio da beleza, do símbolo, da cor, da linha. O uso da mão para a delicadeza, para o bordado, para a costura, para a tecelagem. O corpo se fazendo presente e presença para enfrentar 0 desaparecimento de tantos seres humanos; o coração encontrando forças para se pronunciar através de tapeçarias, estopas, retalhos, fios e lãs.

$\mathrm{Na}$ análise de algumas ações coletivas de mulheres latino-americanas que usaram o bordado como ferramenta política, Alba Pérez Hernández e María Viñolo Berenguel destacam

\begin{abstract}
el papel clave de los movimientos de mujeres como formas alternativas de supervivencia y resistencia al poder establecido, en la fecundación de transformaciones en las relaciones sociales y en los sujetos que las protagonizan, como acciones motivadas por las múltiples desigualdades sociales que comporta una cierta estratificación social [...] En este sentido, este colectivo de mujeres artesanas textiles, crean estrategias propias para luchar a favor de la justicia social, a través de un importante trabajo de empoderamiento, entendido como el proceso de toma de conciencia del poder que individual y colectivamente tienen las mujeres, convirtiéndose en agentes de cambio social. (HERNÁNDEZ; BERENGUEL, 2010, p. 41-42)
\end{abstract}

Para apresentação neste artigo, foram escolhidos três exemplos da utilização do bordado e da costura como formas de superação da dor pessoal e coletiva; como manifestação exterior de situações de opressão, que não queria mais ficar trancafiada no espaço privado. São eles: as Madres de Plaza de Mayo (Argentina); o trabalho das mulheres de Mampuján (Colômbia); Las arpilleras (Chile).

Sob a ótica do território, a análise permite a identificação de especificidades - o uso do espaço público; a desterritorialização; o espaço sagrado para finalidades leigas, entre outras.

\title{
O bordado - brevíssima contextualização espaço-temporal
}

Para além da costura (a união de duas partes por um fio), já desenvolvida na pré-história, surge o bordado, que traz características de ornamentação a essa atividade.

\begin{abstract}
Todo indica que el bordado más antiguo que se ha encontrado en el mundo hasta nuestros días se localiza en la actual América del Sur. Se trata de una estera que ha sido encontrada en el Cementerio Chinchorro, al norte de Chile. $Y$ puede ser datada entre 5.400 y 3.700 a.p. La estera vegetal ha sido bordada con fibra de camélido y cabello humano a base de diseños geométricos $y$, ha sido parte del atuendo mortuorio de los individuos encontrados en dicho cementerio. (Rosa BLANCA, 2014, p. 22)
\end{abstract}

De acordo com Maisa Ferreira de Sousa (2012), outros pesquisadores atribuem aos babilônicos o título de primeiro povo a se dedicar ao desenvolvimento do bordado, seguidos pelos egípcios; propagado pela Europa, popularizou-se nas vestes gregas e, posteriormente, nas romanas. Esta autora afirma ainda que, na ldade Média, o bordado europeu estabeleceu estreita ligação com a igreja católica, com sua utilização nas vestimentas do clero e, com as Cruzadas, suas técnicas são incrementadas na Península lbérica pela presença dos turcos-otomanos, que já possuíam uma grande tradição de bordado.

No continente americano,

A riqueza, a amplitude das técnicas, os elementos decorativos, a vastidão de pontos e técnicas das artes têxteis pré-colombinas [...] desencorajam, ou pelo menos deveria desencorajar, qualquer generalização do tipo que insere estas artes como parte de um saber-fazer 'importado' pelo colonizador. (SOUSA, 2012, p. 6)

Esse também é um ponto afirmado por Annabella Ponce (2013), para quem o tecer é uma das atividades humanas mais antigas, incluindo as culturas pré-hispânicas; os nativos americanos já haviam desenvolvido uma extensa gama de tecidos antes da chegada dos espanhóis em 1492.

\section{Uma atividade feminina e artesanal}

Na Europa da Idade Média, o ensino do bordado acontecia no âmbito familiar e era passado oralmente de mãe para filha. Para as filhas da nobreza, o bordado era ensinado em conventos, como parte da educação feminina, cujo aprendizado de afazeres domésticos tinha por objetivo torná-las boas esposas e mães. No final do século XIX, surgiu a educação pública administrada pelo Estado, com um currículo que incluía trabalhos manuais e domésticos. Construiu-

${ }^{3}$ Evento realizado no instituto Itaú Cultural em São Paulo/SP, nos dias 16 e 17 de março de 2017. 
se no imaginário ocidental, dessa forma, uma estreita relação entre a condição feminina e a prática de trabalhos têxteis e manuais, incluindo o bordado (SOUSA, 2012).

Também na América Latina esta atividade é percebida como realizada pelas mulheres, prioritariamente. Propostas de entendimento das atividades pela ótica dos estudos de gênero podem ser um caminho para ampliar este olhar, como sugere Blanca:

Las actividades artísticas realizadas por mujeres han sido minusvaloradas, rescatándose, en todo caso, las obras edificadas por la mano masculina [...] La óptica de los estudios de género redimensiona áreas de conocimiento como la historia del arte o la estética, al (re)considerar el trabajo y las prácticas femeninas como acciones culturales en distintos contextos que, pueden llegar a producir agencia y autonomía en los espacios tanto íntimos, cuanto públicos y privados [...] Se sugiere que la construcción de la identidad femenina en América Latina y el Caribe está atravesada por determinadas prácticas y disciplinas como el arte y el bordado. (BLANCA, 2014, p. 20)

Além disso, o bordado é visto, na maioria das vezes, como artesanato e não como arte, sendo-lhe atribuído um valor menor, por tratar-se de formas concebidas como precárias em sua realização e desconsideradas as dimensões artísticas de seu fazer. Para Rosa Blanca:

Existe una división jerárquica en el tratamiento de las prácticas artísticas. El arte occidental desdeña el arte y las prácticas estéticas indígenas. Técnicas como cestería, cerámica, arte del cuerpo y bordado, constituyen un tabú en el arte occidental. (BLANCA, 2014, p. 20)

Esta visão do colonizador espanhol, amparada pelas Academias de Belas Artes europeias, deslocou certas práticas artísticas americanas, como o bordado e o trabalho com cerâmica, para o chamado artesanato, retirando-as do lado das técnicas canonizadas, como a pintura e a escultura.

Teresa Isabel Matos Pereira (2016) entende que a associação do bordado e da manufatura têxtil como atividades artesanais e como atividades das mulheres "entrecruza questões culturais, estéticas, de género, sociais, já que sobre si recai uma representação das atividades manuais como formas de diminuir a importância do trabalho feminino (remetida para um espaço da domesticidade)" (PEREIRA, 2016, p. 45).

Há, também, uma desvalorização intrínseca da atividade artística que, como o artesanato, é praticada muitas vezes no âmbito doméstico, geralmente por mulheres, em situações cotidianas e que, por isso, torna-se invisível como prática social importante, passível de reconhecimento público fora do ambiente em que é concebida (Luciana Gruppelli LOPONTE, 2005).

Porém, essa depreciação do artesanato, criada pela divisão artificial da arte entre erudita e popular, vem sendo revista quando órgãos como a Organização das Nações Unidas para a Educação, a Ciência e a Cultura - UNESCO tratam de inseri-lo em outros contextos, apresentando uma visão de seu papel sociocultural e econômico.

La artesanía contemporánea colinda también con las industrias creativas: dada la apertura de la sociedad a adquirir objetos de valor simbólico, la artesanía ha logrado adaptarse a nuevas formas, creando innovadores productos que reflejan a cabalidad la creatividad y el patrimonio cultural de sus creadores. (UNESCO, online)

Em especial, os trabalhos que utilizam um suporte artesanal feminino como instrumento de denúncia e como meio de expressão individual e coletiva - caso dos bordados aqui apresentados - têm sido validados como arte graças a certos discursos artísticos e culturais pós-modernos que vem aceitando nessa categoria novas formas de expressão e resistência (PÉREZ HERNÁNDEZ; VIÑOLO BERENGUEL, 2010).

\section{O sentido identitário do bordado, da costura e da tecelagem}

As manifestações culturais podem ser entendidas como vetores de identidade e memória que ajudam na preservação e disseminação dos valores de um grupo. Como define Claude Raffestin:

A identidade não é somente um estado, mas também e, acima de tudo, um processo. Essencialmente também um processo para se tornar semelhante a quem, no interior de uma área territorial, declara ter as mesmas imagens, os mesmos ídolos, as mesmas normas. (Claude RAFFESTIN, 2015, p. 4, tradução da autora)

Ponce declara que na América Latina as atividades têxteis sempre tiveram importância na identidade dos povos que, desde as culturas pré-hispânicas, as utilizaram para relatar suas ideologias ancestrais, místicas e religiosas, por meio de símbolos. A autora ainda afirma que a tecelagem é um instrumento histórico que conta as mudanças sociais, políticas e econômicas, que incidem na modificação das técnicas desse fazer artesanal (PONCE, 2013).

Os tecidos e tapeçarias, com seus bordados, tornam-se suportes de narrações nas quais vão-se costurando e entrelaçando acontecimentos, histórias, fábulas e mitos. "De esta manera el 
tejido se va constituyendo como símbolo constante de manifestación, no solo cultural, sino también como un discurso a través del cual se van a interpretar diferentes sucesos" (PONCE, 2013, p. 60).

Pereira acredita que, contemporaneamente,

Há na utilização de elementos associados ao universo têxtil um potencial de transformação, onde a criação de imagens-objetos provoca um confronto com estereótipos, fantasmas, receios, expetativas e construções de ordem identitária, cultural e social - que da esfera individual do artista trespassam para o domínio das intersubjetividades partilhadas. (PEREIRA, 2016, p. 45)

Procura-se, neste artigo, enfatizar o uso social do bordado, que sai da esfera de objeto de arte (ou artesanato) para objeto de comunicação, do trabalho particular para o coletivo, da fruição estética para a utilização política. Para além de seu conteúdo artístico, social e político, o bordado implica a sobreposição entre a vida das mulheres que o praticam e o produto artístico resultante, o que pressupõe, como declara Jeanne Marie Gagnebin, que a questão da estética entendida em sua tradução da palavra grega aísthesis, que significa percepção - está ligada ao cotidiano e à política (Marcelo CARVALHO, 2013). Neste sentido, a estética, assim como a política, são formas de tornar visível, de fazer-visível (João Pedro CACHOPO, 2017).

Em suas aproximações com os trabalhos de bordadeiras, em especial as arpilleras, Alba Pérez Hernández y María Viñolo Berenguel entendem que

De esta manera, se materializa el lema de los años setenta "lo personal es político" y convierte las prácticas sociales, en este caso femeninas, en grandes instrumentos estéticos de legitimación. Es en este contexto donde podemos inscribir estas producciones que se presentan como lugares de emergencia de lo real, de denuncias y críticas, y de de-construcción de los modos de representación. (PÉREZ HERNÁNDEZ; VIÑOLO BERENGUEL, 2010, p. 51)

\section{A agulha como instrumento de denúncia e cicatrização}

Nos três exemplos escolhidos, as feridas abertas em cada situação têm origens e causas muito próximas, assim como as marcas que deixaram. Em todas elas, o elemento comum é a agulha, capaz de juntar pedaços, fazer vir à tona o que está silenciado e minimizar as cicatrizes, por meio da arte, da reunião e da comunhão. Nas palavras de Pereira:

Os atos de entrelaçar, coser, bordar [...] assumem-se simultaneamente como exercícios de subversão (ao relatar e denunciar desaparecimentos e assassinatos através de formas de expressão associadas a estereótipos de domesticidade e submissão) mas também de cura já que, através da arte há uma sutura/cicatrização das feridas infligidas ao tecido social. (PEREIRA, 2016, p. 44-45)

\section{Madres de Plaza de Mayo - Buenos Aires/Argentina}

Y si el mundo sobrevive, los profesores de historia explicarán el siglo XX a través de sus símbolos: mostrarán a sus alumnos la botella de Coca-Cola, la pelota de fútbol, el televisor, la computadora, la bomba de neutrones. Y para explicar la dignidad, mostrarán el pañuelo blanco de las rondas de Plaza de Mayo. (Eduardo Galeano)

\section{A Plaza de Mayo}

De acordo com o site oficial de Turismo da Cidade de Buenos Aires, "la Plaza de Mayo es la más antigua de Buenos Aires y escenario de todos los acontecimientos políticos más importantes de la historia argentina, a excepción de la Declaración de la Independencia" (BUENOS AIRES CIUDAD, online).

Lugar da segunda fundação da cidade, em 11 de junho de 1580; na Plaza aconteceram: a Revolución del 25 de Mayo de 1810, que deu início ao processo de independência argentina; em 1890, a fundação da Unión Cívica, partido político que deu origem à Unión Cívica Radical; em 1945, a manifestação organizada por operários para pedir a libertação de Perón, no que posteriormente ficou conhecido como Día de la Lealtad, comemorado anualmente na praça; além de muitos outros atos políticos, manifestações sociais e festas.

Ao seu redor estão localizados vários edifícios históricos e governamentais, como o Cabildo, a Catedral Metropolitana, a Casa de Gobierno (Casa Rosada), o Palácio del Gobierno de la Ciudad, bancos e ministérios; no seu centro encontra-se a Pirámide de Mayo, monumento construído em 1811 para celebrar o primeiro aniversário da Revolución, reformado em 1856.

Como em quase todas as cidades, "a praça é lugar intencional de encontro, da permanência, dos acontecimentos, de práticas sociais, de manifestação de vida urbana e comunitária e de prestígio, e, consequentemente, de funções estruturantes e arquiteturas significativas" (José Manuel LAMAS, 2004, p. 102).

A Plaza de Mayo terá também papel importante como:

Um espaço onde as mães dos desaparecidos durante a última ditadura militar argentina (1976-

1983) adquirem a dimensão política de Madres, em pleno regime ditatorial [...] Sem dúvida, 
esse espaço representa uma paisagem única para a constituição do movimento das Madres, cujo nome provém dele mesmo. Não são "mães" apenas; são as Madres de Plaza de Mayo, um termo com valor semântico que remete à resistência, ao enfrentamento às leis ditatoriais e, reiteradamente, à memória. (Maria Fernanda Garbero de Aragão PONZIO, 2007, p. 1)

\section{Quem Ihe falta?}

Durante a ditadura argentina, algumas mães buscavam individualmente nos escritórios oficiais informações sobre seus filhos desaparecidos. Sem respostas satisfatórias e sem sintonia com os movimentos de denúncia existentes, Azucena Villaflor de Vicenti ${ }^{4}$ propôs a um grupo de 14 mães um encontro na Plaza de Mayo, no dia 30 de abril de 1977, um sábado. A partir dessa data, seguida pela mudança do dia dos encontros para as quintas-feiras, mais mulheres aderiram ao grupo.

Inicialmente, as mães alegavam que "[...] nosotras no hacemos manifestaciones, venimos a testimoniar nuestro dolor, nos han quitado nuestros hijos, le pedimos al gobierno que nos diga dónde están, lo que les pasó" (Jean-Pierre BOUSQUET, 1980 apud PONZIO, 2007, p. 2). Os encontros semanais começam a ser reprimidos, porém elas não se intimidaram e o grupo cresceu em número - quase 150 mulheres - e em organização. A única condição para estar ali era ouvir a pergunta: Quem Ihe falta? A resposta: "um filho...".

Por exigência da polícia, elas não podiam ficar paradas na praça, e eram obrigadas a circular, criando o que viriam a ser as 'rondas' nas quais, às $15 \mathrm{~h} 30$ das quintas-feiras, ao contrário dos ponteiros dos relógios, elas caminham lentamente em busca da justiça em seus passos antihorários (PONZIO, 2007).

Em 1979, as Madres se constituem como uma associação civil que se declara independente de qualquer ideologia, partido político ou crença religiosa. O único princípio de identidade que postulam é o de ter um filho desaparecido. Foi registrada como Asociación Madres de Plaza de Mayo, nome que Ihes foi dado pela população que as via circulando na praça. Para tentar desestabilizar o movimento, o regime militar e os meios de comunicação sob censura se referiam a elas como Las Locas de Plaza de Mayo (Bernard STASI, 1980, p.4)

No início de 1986, algumas divergências causaram a divisão do movimento, com a criação da Madres de Plaza de Mayo Línea Fundadora por oito mães egressas da Asociación (PONZIO, 2007).

\section{Os símbolos - o lenço branco e os bordados}

Na definição de Inés González Bombal:

As Madres da Plaza de Mayo são uma organização cujo objetivo básico foi a denúncia pública, em circunstâncias de censura máxima e perseguição. Por este motivo recorreram a um novo tipo de ato político que se enriqueceu com a incorporação de elementos estéticos, plásticos, rituais, simbólicos etc. As mobilizações eram também produção significante, cujas marcas na cidade terminaram por impactar a opinião pública. Rondas, lenços, fotos, nomes e datas, figuras apresentam a ausência. Colocam um laço entre a cena do ato e a atópica cena da desaparição. (Inés González BOMBAL, 1992, p. 65)

As Madres, muitas delas donas de casa, costureiras e secretárias, de famílias de trabalhadores e da classe média eram, em sua maioria, católicas. Participavam de marchas religiosas, reuniam-se em igrejas e paróquias, utilizavam a reza para escapar das investidas dos policiais e para passar os dados dos próximos encontros às outras mães e adotavam o prego de Cristo, preso em suas roupas, para se identificarem. "Esse prego significava na simbologia católica estar unido a Cristo em sua dor, o que ao ser usado pelas mães significava estabelecer uma relação entre o sofrimento de Cristo ao ser crucificado e a aflição pela qual estavam passando devido ao desaparecimento dos filhos" (Adriana das Graças de PAULA, 2016, p. 5-6).

Quando participaram da peregrinação anual a Luján, Eva Castillo Obarrio propôs o uso de uma fralda como um lenço de cabeça, para que elas pudessem se identificar. Segundo Adriana Paula:

Como sugere Inés Vásquez (2002), a utilização da fralda como um lenço remetia à infância dos filhos, à tentativa de regressar no tempo para proporcionar a eles toda a proteção e vigilância que tiveram de suas mães naquele período. E, também, para mostrar que elas, mães, continuariam zelando por eles do mesmo modo que fizeram quando eram crianças. (PAULA, 2006, p. 7)

As fraldas foram substituídas por lenços brancos e nestes, logo depois, começaram a ser bordados os nomes dos filhos e as datas de seus desaparecimentos.

Com a divisão do movimento, isto se explicita também nos bordados. Os lenços das Madres da Asociación recebem a inscrição Aparición con Vida, em sinal da oposição dessas mães às

\footnotetext{
${ }^{4}$ Sequestrada e morta pelas Forças Armadas no final do ano de 1977.
} 
exumações e identificações de cadáveres e, também, da indenização paga pelo Estado à família do desaparecido, entendidas como aceitação de uma morte que não teve sua causa investigada nem seus culpados punidos. A Línea Fundadora, que continuava com os nomes e datas bordados, considerava essas ações como um modo de reconhecimento pelo Estado de sua responsabilidade pelos crimes de violações (PAULA, 2016, p. 7-8). Na concepção de Maria Fernanda Ponzio:

Confirmada a sua pluralidade nesse encontro semanal dos dois movimentos, o que vemos, também, é a representação simbólica de um momento na luta das Madres da Asociación, em que a dor sai do martírio da cruz para se reproduzir no bordado, no ponto cruz que tece letra por letra e dá forma à frase, cuja ideologia é baseada no discurso e no posicionamento ético. Ao falar que seus desaparecidos seguem vivos em sua luta, e esta passa a representar os ideais dos próprios filhos, elas põem em marcha a construção de um panorama que ultrapassa os limites da Plaza. (PONZIO, 2012, p. 5)

\section{Mujeres Tejiendo Sueños y Sabores de Paz - Mampuján/Colombia O que aconteceu em Mampuján}

Mampuján faz parte da região conhecida como Montes de Maria, no nordeste da Colômbia. Historicamente tem sido um ponto chave na geografia das economias legais e ilegais, bem como uma rota de saída para o Caribe disputada por diferentes grupos armados ${ }^{5}$. Empresas entraram nesta região concentrando grandes quantidades de terra e constituem novas problemáticas de deslocamento, luta pelo controle territorial e corrupção. A presença dos grupos armados e das empresas levaram à transformação da vida de seus moradores, causando grandes danos ao tecido social, à identidade, ao projeto de vida, à cultura e às ancestrais tradições dos habitantes destas terras (Laura Alejandra PARRA, 2014, p. 8).

Em 10 de março de 2000, a comunidade de Mampuján viveu o exílio, destruição e espoliação nas mãos de Bloque Héroes de los Montes de María, grupo paramilitar comandado por Diego Vecino (Edward Cobos Téllez) e Juancho Dique (Úber Banquez Martínez). Foram torturados e assassinados 11 camponeses e aproximadamente 300 famílias foram forçadas a abandonar suas terras, suas casas e seu modo de vida. A comunidade de Mampuján, acusada erroneamente de colaborar com as Forças Armadas Revolucionárias da Colômbia (FARC), dirigiu-se a uma aldeia nas proximidades de María la Baja em Bolivar e, gradualmente, estabeleceu-se em um terreno doado pelo pároco local. Aí, os habitantes da antiga Mampuján começaram a construir, eles mesmos, suas novas casas.

Esta é uma história costumeira na Colômbia, onde milhões de civis foram forçados a deslocarse de suas terras a partir da luta armada entre a guerrilha, o governo e os paramilitares. Grupos designados como de autodefesa camponesa, ou paramilitares, começaram a ser organizados entre as décadas de 1970 e 1980, com a justificativa de suprir a ausência e a incapacidade do Estado no combate às organizações guerrilheiras. Porém, os paramilitares eram patrocinados por latifundiários e empresários ligados ao setor rural, com a ajuda de setores do narcotráfico e seu poder bélico era resultante de fontes ilegais de financiamento. Assim, os paramilitares destacaramse pela brutalidade de seus métodos, acompanhados por incontáveis massacres, associados a programas de eliminação ou desaparecimento seletivo, além de despovoamento forçado (Víctor Manuel Moncayo CRUZ, online).

Mas a história de Mampuján é considerada diferente da de outras localidades onde aconteceram situações semelhantes. E um dos motivos foi a iniciativa de Juana Alicia Ruiz Hernández, que se converteu em uma das líderes mais ativas da comunidade, vinculando-se ao projeto Sembrando Paz, que ajuda comunidades a recuperarem-se das marcas traumáticas dos deslocamentos forçados. Juana Alicia nasceu em 1973, em San Pablo, Colômbia, em uma família de camponeses, sendo a mais nova de onze filhos. Criou-se nas montanhas dos Montes de María até que, dos 6 aos 9 anos, foi viver na Venezuela com sua mãe. Ao regressar, frequentava a escola primária e trabalhava no mercado. Durante esses anos, e no começo de sua juventude, Juana enfrentava suas dificuldades desenhando. Estudou Nutrição na Universidad del Atlántico, em Barranquilla, Colômbia. Aos 19 anos, converteu-se à doutrina evangélica e, um ano depois, com um grupo de jovens evangelistas foi pela primeira vez a Mampuján, onde conheceu Alexander, com quem se casaria. No ano 2000 , quando houve o deslocamento forçado os habitantes, Juana ainda não vivia na comunidade; em 2003, já casada e grávida, foi viver em María La Baja, próximo à nova Mampuján. Convidou, então, a psicóloga e artista estadunidense Teresa Geisere,

\footnotetext{
${ }^{5}$ Entre os grupos armados colombianos, encontram-se as guerrilhas, os paramilitares o a Força Pública estatal. As guerrilhas não foram um ator homogêneo no conflito armado na Colômbia; ao contrário, emergiram uma pluralidade de organizações armadas que lutaram contra o Estado, reivindicando diferentes paradigmas ideológicos e que, muitas vezes, provocaram intensas e violentas disputas entre si. Os grupos paramilitares, historicamente armados, são muito diversos e com muita autonomia. A Força Pública inclui as forças Armadas (que contam com o Exército Nacional, a Força Aérea Colombiana e a Armada Nacional) e a Polícia Nacional (GMH, 2013, p. 34).
} 
e junto com as outras mulheres, começaram a desenvolver um trabalho por meio dos bordados, como forma de resistência e preservação da memória (Hernán URBINA JOIRO, online).

\section{O bordado}

Juana Alicia reuniu as mulheres em um projeto de bordado, o que as motivou a falar de seus sentimentos e de suas experiências enquanto iam bordando suas próprias histórias. O projeto demonstrou ser uma forma criativa de libertar a raiva e a tristeza e, assim, começar um processo de cura. Nascia então, o grupo Mujeres Tejiendo Sueños y Sabores de Paz.

Gloria Castrillón, editora especializada em coberturas jornalísticas de conflitos armados, ao descrever o trabalho deste grupo de mulheres, disse que:

Las primeras puntadas fueron de dolor. Cada vez que entraba la aguja para unir las telas, algo se desgarraba en su corazón y el llanto salía sin parar. Entonces estas mujeres soltaban la aguja y se secaban las lágrimas para seguir llorando. La colcha de retazos apenas tenía forma: unas montañas de fondo, unos caminos, algunos árboles y el arroyo; ahora tenían que dibujar las personas. Cada figura representaba a un vecino, amigo o familiar. Por eso dolía tanto, porque lo que estaban plasmando en la tela era su propia historia. (Gloria CASTRILLÓN, 2015 , on-line)

As primeiras tapeçarias que criaram chamaram-se Día de Llanto e Desplazamiento e traziam, justamente, as imagens e acontecimentos daquele 10 de março. Elas foram uma ferramenta em busca da reconciliação com o passado. Em sua análise sobre as mulheres bordadeiras de Mampuján, Laura Parra entende que:

Estos tapices funcionaron para estas mujeres como un amplio repertorio de memorias de la opresión histórica a la que habían sido sometidas, así como un escenario de encuentro, florecimiento y espiral comunitaria que les dio la posibilidad de dialogar, anudar los hechos, sanar heridas y trasformar desde allí relaciones. De este modo, las iniciativas del tejido iniciaron como una forma de "historiar experiencias humanas de sufrimiento" y documentar la respuesta cultural de las mujeres frente al conflicto armado, y la dominación histórica del colonialismo sobre la comunidad negra, y se fue convirtiendo en un escenario de conexión sobre la base de la identidad, el territorio y las relaciones cotidianas que les permitió transformar sus vidas en situación de desplazamiento y construir sobre la adversidad nuevas formas de ser y estar en el mundo. (PARRA, 2014, p. 21)

Juana e suas companheiras quiseram compartilhar essa experiência de cura. Conseguiram um financiamento da Organização das Nações Unidas (ONU) para o que chamaram ruta por la vida e que consistiu em percorrer os mesmos lugares que haviam sido percorridos pelos paramilitares enquanto espalhavam a morte e o terror e que, para elas, serviu para trabalhar e retirar sua dor e a expressar em uma tapeçaria.

Em 2015, o grupo Mujeres Tejiendo Sueños y Sabores de Paz de Mampuján ganhou o Prêmio Nacional da Paz por sua capacidade de fazer, dos tecidos artesanais, um ponto de partida para o processo de reconciliação, memória e reparação.

\section{Território, justiça, paz e perdão}

O território perdido, a antiga Mampuján, era um espaço cotidiano carregado de práticas culturais, que permitia aos moradores construir redes econômicas, culturais e sociais sólidas. Também se conformaram os modos particulares de solidariedade e reciprocidade, ancorados na conexão dos sujeitos com o coletivo, alimentados por uma linguagem comum, uma história compartilhada e expressões culturais surgidas ali. Com o deslocamento, as formas cotidianas de vida se fraturaram completamente (PARRA, 2014).

Para Marcelo Souza, o processo de desterritorialização:

pode ter a ver com o desenraizamento (menos ou mais traumático culturalmente) de indivíduos e grupos e pode implicar a privação do acesso a recursos e riquezas; mas é, sempre, e em primeiro lugar, um processo que envolve o exercício de relações de poder e a projeção dessas relações no espaço. (Marcelo Lopes de SOUZA, 2015, p. 56, grifos no original)

Em um dos trabalhos (Figura 1), feito em 2013, as mulheres bordaram como imaginam seu retorno para sua aldeia natal, com casas reconstruídas, crianças brincando, adultos engajados nas tarefas cotidianas, em um cenário idílico; enquanto umas imaginam um retorno utópico, as mais realistas sabem que muitos desafios estão por vir (Conflict Archive on the Internet - CAIN, on-line).

Outro trabalho, também de 2013 (Figura 2), realizado por 15 participantes do grupo Mujeres tejiendo sueños y sabores de paz, de Mampuján, prevê seu retorno oito anos depois a uma comunidade livre de violência. A figura central, vestida de branco, com seu rifle quebrado e roupas militares jogadas de lado, é um poderoso símbolo de paz quando declara "No Mas - Eu não vou mais fazer isso." (Conflict Archive on the Internet - CAIN, online). 


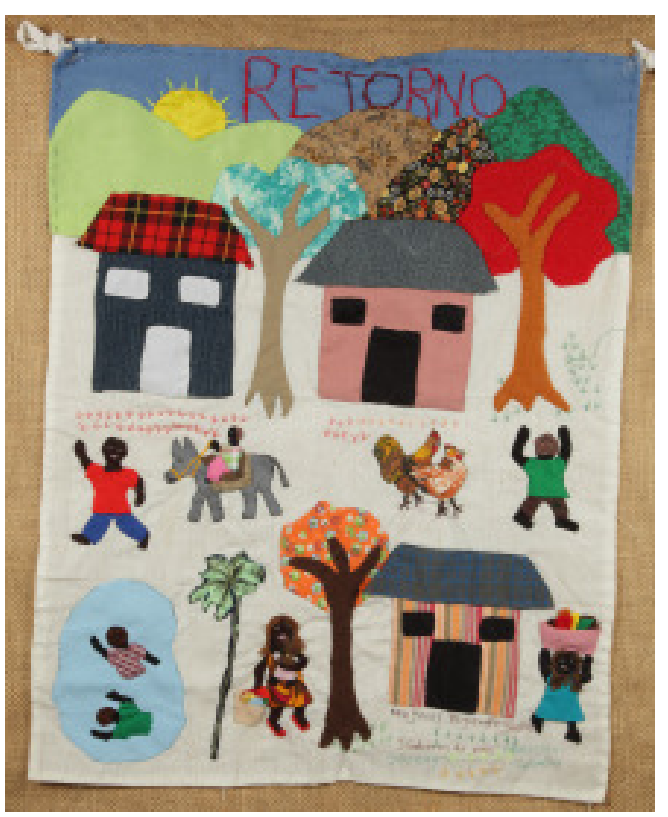

Figura 2

Nomas / No more (2013)

Arpillera Colombiana, Mujeres tejiendo sueños y sabores de paz, Manpuján,

Foto: Martin Melaugh (c) Conflict Textiles. http:// cain.ulster.ac.uk/conflicttextiles

\#PraCegoVer Essa arpillera prevê o retorno a uma comunidade, Mampuján, livre de violência. Apresenta uma figura central vestida de branco, com seu rifle quebrado e roupas militares jogadas de lado. De boca aberta e com as mãos levantadas, ele olha para cima declarando: "NÃO MAIS - Eu não vou mais fazer isso." No céu noturno, a pomba branca da paz é visível emoldurada pela lua, enquanto em primeiro plano vêem-se colheitas crescentes e casas retratadas nas cores vibrantes do povo afro-colombiano.

\section{Figura 1}

Retorno / Return (2013)

Arpillera Colombiana, Mujeres tejiendo sueños y sabores de paz, Manpuján

Foto: Martin Melaugh (c) Conflict Textiles. http:// cain.ulster.ac.uk/conflicttextiles

\#PraCegoVer Esta arpillera mostra como as mulheres imaginam seu retorno para sua aldeia natal, Mampuján, apresentada como idílica. Casas são reconstruídas, crianças brincam, adultos estão engajados nas tarefas diárias da vida da aldeia nesta área aparentemente fértil, contra o pano de fundo de colinas ondulantes e um sol amarelo brilhante.

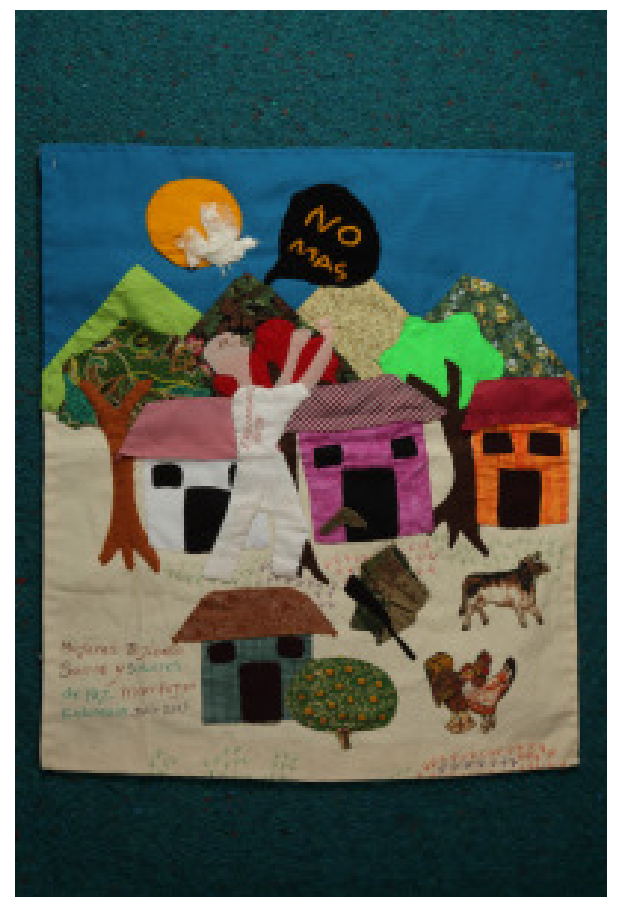

O caso de Mampuján tem várias particularidades, sendo que a mais importante é que, pela primeira vez no contexto de Justicia y Paz ${ }^{6}$ se falou em "danos coletivos", ou seja, se reconheceu a comunidade inteira como vítima. Por isso, para a reparação, concluiu-se que os acusados seriam responsabilizados pela ruptura do tecido social; pela desterritorialização; pelo ataque à identidade cultural e às tradições ancestrais; pela desarticulação dos movimentos sociais e econômicos; pela imposição de um modelo violento e autoritário nas relações da comunidade; e pela estigmatização dos camponeses que seguem sendo apontados como supostos guerrilheiros nas cidades em que buscaram refúgio há mais de dez anos (María Juliana ROJAS BERRíO, 2015).

Em junho de 2010, Diego Vecino e Juancho Dique foram condenados pelo Tribunal Superior de Bogotá a penas de 39 e 38 anos respectivamente pelo massacre dos 11 camponeses e pela desterritorialização das 300 famílias em Mampuján. Foram uns dos poucos paramilitares condenados pela Justicia y Paz.

Grande parte da comunidade de Mampuján, em um feito inédito no país, perdoou esses homens. De acordo com o Informe del Centro de Memoria Histórica (2012), a audiência de reparação é o momento em que o processo inclui a participação direta de instituições e de vítimas. Por isso, a audiência de Vecino e Dique contou com a presença de algumas vítimas e foi transmitida para a comunidade, que a assistiu reunida no campo de futebol e transformou-se em um episódio inédito e inesperado, assim relatado

${ }^{6}$ Ley de Justicia y Paz (Ley 975 de 2005) é um marco jurídico promovido pelo governo de Álvaro Uribe, criado para facilitar o processo de desmobilização de paramilitares na Colômbia e que podia, eventualmente, ser utilizado também no processo de desmobilização de grupos guerrilheiros. 
En el marco de una escena asombrosa, en la cual los asistentes pudimos observar de todo, incluidas víctimas que biblia en mano atravesaron de repente las barreras invisibles que marcan los espacios dentro de los cuales se despliegan los roles judiciales en la sala de audiencias de Justicia y Paz en Bogotá, para acercarse a sus victimarios y abrazarlos [...] (CENTRO DE MEMORIA HISTÓRICA, 2012, p. 593)

Esta ação de perdão foi iniciada pelas mulheres bordadeiras que, além da recuperação da memória, trabalharam na construção da paz. O homem que entregou a Bíblia era Alexander Villarreal, marido de Juana Alicia (Ana VOGT, 2015).

\section{Las Arpilleras - Chile}

Qué te cuesta mujer árbol florido Álzate en cuerpo y alma del sepulcro Y haz estallar las piedras con tu voz Violeta Parra

\section{Contexto político chileno}

Em 11 de setembro de 1973, um golpe de Estado derrubou o presidente eleito Salvador Allende e levou ao poder uma junta militar liderada pelo general Augusto Pinochet. O regime foi caracterizado pela supressão sistemática de partidos políticos e pela perseguição de dissidentes a uma extensão sem precedente na história do Chile. A democracia só foi restaurada em 1990. 0 reconhecimento oficial da verdade e a quantificação das vítimas foram sendo estabelecidos gradualmente e ao longo do tempo, em diversas instâncias promovidas pelo Estado chileno. A Comisión Asesora Presidencial para la Calificación de Detenidos Desaparecidos, Ejecutados Políticos y Víctimas de Prisión Política y Tortura (Comisión Valech II), constituída em fevereiro de 2010, após um trabalho de 18 meses, estabeleceu a cifra oficial de vítimas reconhecidas de prisão política e tortura no período da ditadura em38.254 pessoas (INSTITUTO NACIONAL DE DERECHOS HUMANOS, 2017, p. 195).

\section{História das arpilleras}

A arpillera é uma técnica têxtil que possui raízes numa antiga tradição popular de um grupo de bordadeiras de Isla Negra, localizada no litoral central chileno. São montadas em panos rústicos provenientes de sacos de farinha ou batatas, geralmente fabricados em cânhamo, linho grosso ou juta, e isso deu o nome a essa expressão artística. Toda a costura é feita à mão e às vezes são adicionados fios de lã ou em crochê para realçar os contornos das figuras. O tamanho dessas obras era determinado pela dimensão do saco. Uma vez consumido seu conteúdo, ele era lavado e cortado em seis partes, possibilitando assim que o mesmo número de mulheres bordasse sua própria história, a de sua família e de sua comunidade (Roberta BACIC, 2012).

Como mostra o artigo El coser, tejer, bordar, son y representan escrituras femeninas que cuentan lo que la palabra o el habla no pueden decir (Marjorie AGOSíN, 1985, p. 523), muitas mulheres chilenas, durante a ditadura, precisaram resistir, combater e não deixar cair no esquecimento seus filhos, maridos e irmãos, torturados e desaparecidos. Para isso, encontraram na confecção das arpilleras uma forma de socializar e trabalhar suas dores, bem como uma fonte de sobrevivência.

As arpilleras, como expressão de um discurso concreto e vivido, saíam do ambiente privado e silencioso da mulher para serem objetos de denúncia e enfrentamento; mostravam o que realmente estava acontecendo nas vidas de suas bordadeiras; representavam a luta pela verdade e pela justiça, além de se apresentarem como uma forma de quebrar o código de silêncio imposto pela situação então vivida no país. Na expressão de Marjorie Agosín

Es éste el fenómeno de las arpilleristas chilenas, quienes, utilizando un arte netamente doméstico - por lo de ama de casa y por ser ejecutado dentro del limitado perímetro del hogar -, cobran una fuerte tonalidad subversiva y testimonial dentro y fuera de Chile. En consecuencia, la imagen de la dócil ama de casa que trabaja pacientemente con retales y coloca armoniosamente los diseños superpuestos en una tela ordinaria, invierte radicalmente su función social transformando a este arte pasivo en una activa protesta donde la mujer, por medio de su propia escritura, crea una dinámica vital en la historia de su país. (AGOSíN, 1985, p. 523-524)

\section{Espaços sagrados e profanos}

Criado em 1976 pelo cardeal chileno à época, monsenhor Raúl Silva Henríquez, o Vicariato de Solidariedade tinha por finalidade ajudar as vítimas de violações dos direitos humanos, prosseguindo a tarefa iniciada pelo Comitê de Cooperação para a Paz no Chile, que foi obrigado a se dissolver pela pressão do governo militar. Este também era o objetivo da Fundação Social de 
Ajuda das Igrejas Cristãs (Fasic). Nas dependências do Vicariato funcionava o Grupo de Familiares de Presos Desaparecidos, e na Fasic se reuniam os integrantes do Grupo de Familiares de Executados Políticos e o Grupo de Ex-Presos Políticos. As oficinas de arpilleras nasceram e se difundiram com a ajuda dessas instituições.

Em um exemplar de arpillera realizada na oficina do Vicariato de Solidariedade, em 1983 (Figura 3), vê-se o empobrecimento causado pelas políticas econômicas do regime de Pinochet como, por exemplo, o uso irregular da fiação da rede elétrica. Apresenta, também, a distribuição de sopa, única fonte de alimento de muitos chilenos, provocando indignação ao mostrar a ação do policial armado que, apoiado por um carro de polícia, derruba todo o conteúdo da panela de sopa no chão (Conflict Archive on the Internet - CAIN, on-line).

Reunidas também dentro de igrejas, onde os militares não entravam, as mulheres começaram a se fortalecer como grupo.

Se les ofreció un refugio, un lugar donde pudieran compartir sus experiencias conjuntas con otras mujeres. Experiencias que prontamente se plasmarían en los retazos de género que les fueron proporcionados con el fin de que desarrollaran un trabajo productivo que les permitiera mantenerse ocupadas y olvidar por momentos el sufrimiento, y obtener también algo de dinero para sus familias; una labor, diríamos, de sobrevivencia emocional y económica. (MUNICIPALIDAD DE SANTIAGO, 2012, online)

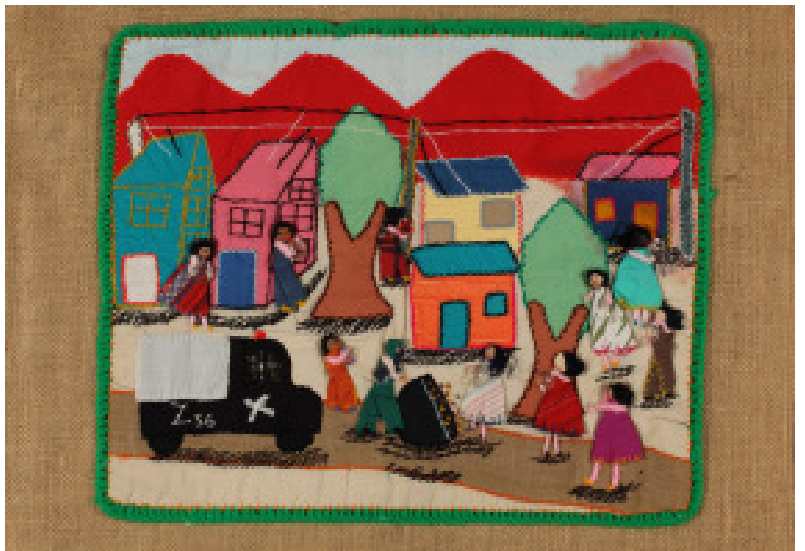

Figura 3

Carabineros tumbando olla común / Police tumbling soup kitchen (1983)

Arpillera Chilena, Taller Vicaría de la Solidariedad

Foto: Martin Melaugh (c) Conflict Textiles. http://cain.ulster.ac.uk/ conflicttextiles

\#PraCegoVer Esta arpillera mostra o uso irregular da fiação da rede elétrica entre as casas, sobre um fundo montanhoso em vermelho. Apresenta também a distribuição de sopa, e a indignação provocada pela ação do policial armado que, apoiado por um carro de polícia, derruba todo o conteúdo da panela de sopa no chão.

\section{Figura 4}

Al servicio de la vida / Servicing life (1978c) Arpillera Chilena, Anônimo.

Foto: Martin Melaugh (c) Conflict Textiles. http:// cain.ulster.ac.uk/conflicttextiles

\#PraCegoVer Esta arpillera retrata o tipo de atividades e áreas de apoio que a igreja católica empreendeu para ajudar uma parte substancial da população perseguida e abandonada pela ditadura de Pinochet. Mostra a sede da igreja onde proble-mas como a defesa legal, o exílio, a prisão políti-ca, os detidos desaparecidos e a apresentação de habeas corpus aos tribunais estão sendo tratados em nome da população local.
O território é "um espaço político, um jogo político, um lugar de poder. Definir seus limites, recortá-lo, é sinônimo de dominação, de controle" (Rosa Maria Vieira MEDEIROS, 2015, p. 215216). Ao estabelecer sua autoridade no interior do espaço sagrado, a Igreja afirmava sua resistência ao regime ditatorial. E, ao abrir esse mesmo espaço para atividades profanas, permitiu sua ocupação, cujo sentido se entrelaçava com outras ações na constituição de um movimento social e afetivo.

As atividades realizadas pelas igrejas católicas estão retratadas nesta arpillera de 1978, de autoria anônima (Figura 4), que mostra a sede de uma igreja como local onde problemas como a defesa legal, o exílio, a prisão política, os detidos desaparecidos e a apresentação de habeas corpus aos tribunais estão sendo tratados, em nome da população local (Conflict Archive on the Internet - CAIN, on-line). 


\section{Contra-arpilleras}

O Centro de las Madres (CEMA) é uma fundação chilena criada em1954, no governo de Carlos Ibáñez del Campo, definida como

Una corporación de derecho privado, sin fines de lucro, ajena por completo a proselitismo político o religioso, cuyo principal objetivo es lograr el desarrollo integral de la mujer agrupada en los Centros de Madres a lo largo y ancho del país, y por intermedio de ellos, contribuir al bien estar de su familia. (Norbert LECHNER; Susana LEVY, 1984, p.7)

A instituição ficou conhecida durante o Regime Militar dirigido por Augusto Pinochet, quando sua presidência esteve, a partir de 1973, nas mãos da primeira dama Lucía Hiriart de Pinochet, considerada "la máxima autoridad en las acciones destinadas a mujeres" (FLACSO, on-line). O CEMA passou a ter uma extensa rede de monitoras voluntárias, geralmente esposas de militares, que promoveram uma doutrinação de mulheres. Suas sedes foram instaladas em terrenos cedidos gratuitamente pela junta militar.

Para tentar mostrar ao mundo uma imagem de um Chile sem problemas, mascarar a história e desacreditar as bordadeiras que lutavam contra o regime, no Centro de las Madres foram realizadas contra-arpilleras, com materiais de maior qualidade e que mostravam, nas peças, um mundo silencioso e quase perfeito, longe da realidade das arpilleristas.

Não passou despercebido ao governo Pinochet que, por trás da aparente simplicidade de seus bordados, as arpilleras eram poderosos instrumentos de denúncia e testemunho de uma realidade que se queria camuflar e que, por trás do colorido de suas tapeçarias estavam sempre aparentes a desolação e a injustiça que procuraram revelar.

\section{Considerações finais}

O existir, para as mulheres na América Latina, passa, muitas vezes, pelo enfrentamento de condições adversas, principalmente em períodos de governos ditatoriais ou pela dominação do tráfico em certos territórios. Apesar de não ter seu papel valorizado e exposto - estatuto quase sempre oferecido aos homens - as mulheres encontram pela sensibilidade formas de manejar as dificuldades, e são elas que acabam por assumir o controle do que restou de suas comunidades e famílias.

Ocupando, pela necessidade, espaços de transição, procuram dotá-lo de certa materialidade, mas visam, principalmente, reconstruir nos novos territórios as relações sociais corrompidas pelos eventos traumáticos, pelos desaparecimentos e pelas mortes.

Saindo do recesso de suas casas, juntando forças, cumprem essa espera nostálgica - mas nunca resignada -, auxiliadas pelas agulhas e explicitadas em seus bordados, nos levando à quase inevitável comparação a Penélopes contemporâneas, a personagem de Homero na Odisseia que, por meio do fazer e refazer de seu bordado, tece ao redor de si uma teia de esperança na espera por seu marido Ulisses, em um ato de desafio aos homens que a rodeiam.

Neste momento, valem-se da memória para refazerem a vida e recomeçarem, escolhendo o que guardar, o que esquecer e o que mostrar. Como diz Michael Pollak (1992, p. 204), "a memória é um fenômeno construído", ou seja, a memória é resultado de um trabalho de organização: ela grava, exclui, recalca, relembra. Em seus trabalhos, as mulheres escolhem apresentar uma outra memória, singular e coletiva, excluída da história oficial e, com isso, tornam visíveis seu protagonismo como agentes de mudança social.

Para essas mulheres, a reconstrução está em cada ponto bordado, na tentativa de que, juntos, eles possam ser veículos de solidariedade e sejam os fios que nunca as separem do que mais buscam: a justiça, a esperança e a vida.

\section{Referências}

AGOSÍN, Marjorie. "Agujas que hablan: las arpilleristas chilenas". Revista lberoamericana, Pittsburgh, University of Pittsburgh Press, v. LI, n. 132-133, p. 523-529, julio-diciembre. 1985. Disponível em https://revista-iberoamericana.pitt.edu/ojs/index.php/lberoamericana/article/view/4066/4234. Acesso em 31/05/2017.

BACIC, Roberta. Arpilleras da resistência política chilena. Brasília: Biblioteca Nacional, 2012. Disponível em http://cain.ulster.ac.uk/conflicttextiles/mediafiles/178_2011-07-30_SaoPaulo_catalogue.pdf. Acesso em 30/05/2017.

BLANCA, Rosa. "El Bordado en lo Cotidiano y en el Arte Contemporáneo: ¿Práctica Emergente o Tradicional?" Revista Feminismos, Salvador, Núcleo de Estudos Interdisciplinares sobre a Mulher NEIM da Universidade Federal da Bahia, v. 2, n. 3 p. 19-30, set/dez. 2014. Disponível em http:// www.feminismos.neim. ufba.br/index.php/revista/article/download/93/123. Acesso em 30/05/2017. 
BOMBAL, Inés González. "De Vítimas a Sujeitos: as Mães da Plaza de Mayo". Revista de Ciência Humanas, Florianópolis, Centro de Filosofia e Ciências Humanas da UFSC, v. 8. n. 11, p. 49-70, maio. 1992. Disponível em https://periodicos.ufsc.br/index.php/revistacfh/article/viewFile/23524/ 21182 . Acesso em 28/05/2017.

BUENOS AIRES CIUDAD. Plaza de Mayo [online]. Sitio oficial de turismo de la Ciudad de Buenos Aires. Buenos Aires, Argentina. Disponível em https://turismo.buenosaires.gob.ar/es/otrosestablecimientos/plaza-de-mayo. Acesso em 28/05/2017.

CACHOPO, João Pedro et al.. Estética e política entre as artes. Lisboa: Edições 70, 2017.

CARVALHO, Marcelo. "Estética, política e cotidiano: Entrevista com Jeanne Marie Gagnebin”. In: CARVALHO, Marcelo, CORNELLI, Gabriele (orgs.). Filosofia: estética e política. Vol. 3. Cuiabá: Central de Texto, 2013. p. 109-128.

CASTRILLÓN, Gloria. "Las tejedoras de Mampuján: la fuerza feminina del perdón”. Revista Cromos [online]. Colômbia. 19 de novembro de 2015. Disponível em http://cromos.elespectador.com/hoyhistorias-cronicas/las-tejedoras-de-mampujan-la-fuerza-femenina-del-perdon-16675. Acesso em 29/05/2017.

CENTRO DE MEMORIA HISTÓRICA. Informe: Justicia y Paz ¿Verdad Judicial o Verdad Histórica? Colombia: Taurus Pensamiento, 2012.

CONFLICT ARCHIVE ON THE INTERNET - CAIN. Conflict Textiles. Disponível em http://cain.ulster.ac.uk/ conflicttextiles/. Acesso em 21/07/2017.

CRUZ, Víctor Manuel Moncayo. Enciclopédia Latinoamericana [online] Verbete. Disponível em http://latinoamericana. wiki.br/verbetes/c/colombia-organizacoes-paramilitares-da. Acesso em 20/ 09/2017.

FLACSO - Facultad Latinoamericana de Ciencias Sociales. Acción de las Primeras Damas. Santiago, Chile, s/d. Disponível em http://www.eurosur.org/FLACSO/mujeres/chile/orga-6.htm. Acesso em 27/05/2017.

GMH - GRUPO DE MEMORIA HISTÓRICA. Informe General: iBasta ya! Colombia: Memorias de Guerra y Dignidad. Bogotá: Imprenta Nacional, 2013.

PÉREZ HERNÁNDEZ, Alba; VIÑOLO BERENGUEL, María. "Las arpilleras, una alternativa textil femenina de participación y resistencia social”. In: GIL, Carmen Gregório; BLANCO, Patricia. ¿Por qué tienen que decir que somos diferentes? Las mujeres inmigrantes, sujeitos de accíon política. S/local, Otras, 2010. p. 41-54.

INSTITUTO NACIONAL DE DERECHOS HUMANOS. Informe Anual: Situación de los Derechos Humanos en Chile 2017. Santiago de Chile, dezembro de 2017.

LAMAS, José Manuel Ressano Garcia. Morfologia Urbana e Desenho da Cidade. Lisboa: Fundação Calouste Gulbenkian, 2004.

LECHNER, Norbert; LEV, Susana. "Notas sobre la vida cotidiana III: el disciplinamiento de la mujer". Programa Flacso-Santiago de Chile. Santiago de Chile. FLACSO, Número 57, p. 1-101. Julio 1984. Disponível em http://www.memoriachilena.cl/602/w3-article-61041.html. Acesso em 30/05/201 7.

LOPONTE, Luciana Gruppelli. Docência artística: arte, estética e subjetividades femininas. 2005. Tese (Doutorado em Educação) - Programa de Pós-Graduação em Educação. Faculdade de Educação da UFRGS, Porto Alegre, RS, Brasil.

MEDEIROS, Rosa Maria Vieira. "Território, espaço de identidade". In: SAQUET, Marcos Aurelio; SPOSITO, Eliseu Savério (Orgs.). Territórios e Territorialidades: teorias, processos e conflitos. 2. ed. Rio de Janeiro: Consequência Editora, 2015. p. 215-225.

MUNICIPALIDAD DE SANTIAGO. Tradición de arpilleras en Chile. 7 de noviembre de 2012. Disponível em http://www.santiagocultura.cl/2012/11/07/tradicion-de-arpilleras-en-chile/. Acesso em 29/05/ 2017.

PARRA, Laura Alejandra. Entre puntadas, palabras y duelos, las 'Tejedoras de sueños' en Mampuján aportan a la construcción de paz. 2014. Monografia (Especialização em Trabalho Social) - Facultad de Ciencias Humanas da Universidad Nacional de Colombia, Bogotá, Colômbia. 
PAULA, Adriana das Graças de. "Os Movimentos de Mulheres na Ditadura: uma análise sobre as Mães da Praça de Maio (Argentina) e o Movimento Feminino pela Anistia (Brasil)". In: II SIMPÓsIO INTERNACIONAL PENSAR E REPENSAR A AMÉRICA LATINA, 2., 2016, São Paulo, PROLAM, USP. Anais do II Simpósio Internacional Pensar e Repensar a América Latina. São Paulo: USP, 2016. p. 1-11. Disponível em http://sites.usp.br/prolam/wp-content/uploads/sites/35/2016/12/PAULA_II-Simp\%C3\%B3sioInternacional-Pensar-e-Repensar-a-Am\%C3\%A9rica-Latina.pdf. Acesso em 29/05/2017.

PEREIRA, Teresa Isabel Matos. "Suturar e Bordar: o têxtil como metáfora de identidade, memória e violência na obra de Claúdia Contreras". Revista CROMA, Estudos Artísticos, Lisboa, Faculdade de Belas-Artes da Universidade de Lisboa e Centro de Investigação e Estudos em Belas-Artes (FBAUL/ CIEBA), v. 4, n. 8, p. 43-55, julho-dezembro. 2016. Disponível em http://croma.fba.ul.pt. Acesso em 27/05/2017.

POLLAK, Michael. "Memória e identidade social". Trad. Monique Augras. Estudos Históricos, Rio de Janeiro, Programa de Pós-Graduação em História, Política e Bens Culturais (PPHPBC) do CPDOC/FGV, v. 5, n. 10, p. 200-212, jul/dez. 1992. Disponível em http://bibliotecadigital.fgv.br/ojs/index.php/reh/ article/view/1941/1080. Acesso em 28/04/2017.

PONCE, Annabella. El tejido como relato social. 2013. (Doutorado em Desenho) - Centro de Estudios en Diseño y Comunicación. Facultad de Diseño y Comunicación da Universidad de Palermo, Ciudad de Buenos Aires, Argentina. Disponível em http://fido.palermo.edu/servicios_dyc/ tesis_maestria/detalle_proyecto.php?id_proyecto=2460. Acesso em 27/05/2017.

PONZIO, Maria Fernanda Garbero de Aragão. "A praça da memória: o cenário das Madres de Plaza de Mayo". Palimpsesto. Rio de Janeiro, Revista do Programa de Pós-Graduação em Letras da UERJ, v. 6, ano 6, p. 1-7, jan/dez. 2007. Disponível em http://www.pgletras.uerj.br/palimpsesto/ numb/estudos/estudos6_Maria\%2OFernanda\%20Garbero.htm. Acesso em 28/05/201 7.

RAFFESTIN, Claude. "A produção das estruturas territoriais e sua representação'. In: SAQUET, Marcos Aurelio; SPOSITO, Eliseu Savério (Orgs.). Territórios e Territorialidades: teorias, processos e conflitos. 2. ed. Rio de Janeiro: Consequência Editora, 2015. p. 12-32.

ROJAS BERRÍO, María Juliana. "Mampuján en el acto de partir: el duelo como levantamiento y la comunidad en transición". Revista de Estudios Sociales, Bogotá, Facultad de Ciencias Sociales, Universidad de los Andes (Colombia), n. 51, p. 50-61, janeiro/março. 2015. Disponível em http:// www.scielo.org.co/pdf/res/n51/n51 a05.pdf. Acesso em 28/05/2017.

SOUSA, Maisa Ferreira de. O bordado como linguagem na arte/educação. 2012. (Graduação em Artes Plásticas) - Departamento de Artes Visuais do Instituto de Artes da UnB. Brasília, DF, Brasil. Disponível em http://bdm.unb.br/bitstream/10483/4494/1/2012_MaisaFerreiradeSousa.pdf. Acesso em 25/05/2017.

SOUZA, Marcelo Lopes de. "'Território' da divergência (e da confusão)”. In: SAQUET, Marcos Aurelio; SPOSITO, Eliseu Savério (Orgs.). Territórios e Territorialidades: teorias, processos e conflitos. 2. ed. Rio de Janeiro: Consequência Editora, 2015. p. 53-68.

STASI, Bernard. "La llamada de 'Las Locas de Mayo' a la consciência europea”. In: Dossier Político. Ciudad de Mexico, México, Edicos - Equipo de Documentación e Investigación em Comunicación Social. Ano 1, n. 2, p. 3, 19. quincena - junio. 1980. Disponível em http://www.ruinasdigitales.com/ revistas/ddhh/1980\%20-\%20Locas\%20de\%20Plaza\%20de\%20Mayo.pdf. Acesso em 30/05/201 7.

UNESCO. Industrias criativas: Artesanía y Diseño [online]. Disponível em http://www.unesco.org/new/ es/santiago/culture/creative-industries/crafts-design/. Acesso em 28/1 1/2017.

URBINA JOIRO, Hernán. Juana Alicia Ruiz y las Tejedoras de Sueños de Mampuján. Disponível em https://hernan-urbina-joiro.com/juana-alicia-ruiz-y-las-tejedoras-de-suenos-de-mampujam/. Acesso em 21/07 2017.

VOGT, Ana. Quilts of hope. The City Paper. 24 de fevereiro de 2015 [online]. Disponível em https:// thecitypaperbogota.com/features/quilts-of-hope76778/8413. Acesso em 28/1 1/2017.

Renata Rendelucci Allucci (renata@3d3.com.br/renata.ra@puccampinas.edu.br) é doutoranda em Urbanismo pela Pontifícia Universidade Católica de Campinas; mestra em História pela Pontifícia Universidade Católica de São Paulo; especialista em Bens Culturais pela FGV/SP. Produtora cultural desde 1994. Pesquisadora nas áreas de cultura, festas populares, patrimônio cultural e urbanismo. 
COMO CITAR ESSE ARTIGO DE ACORDO COM AS NORMAS DA REVISTA

ALLUCCI, Renata Rendelucci. "Una aguja, una lámpara, un telar". Revista Estudos Feministas, Florianópolis, v. 27, n. 3, e54376, 2019.

\section{CONTRIBUIÇÃO DE AUTORIA}

Não se aplica

\section{FINANCIAMENTO}

Doutoranda bolsista da CAPES - O presente trabalho foi realizado com apoio da Coordenação de Aperfeiçoamento de Pessoal de Nível Superior - Brasil (CAPES) - Código de Financiamento 001

\section{CONSENTIMENTO DE USO DE IMAGEM}

Foi obtida autorização de uso para as 4 imagens abaixo apresentadas. Todas as imagens têm (C) copyright of Roberta Bacic / CAIN Conflict Textiles.

APROVAÇÃO DE COMITÊ DE ÉTICA EM PESQUISA

Não se aplica

\section{CONFLITO DE INTERESSES}

Não se aplica

\section{LICENÇA DE USO}

Este artigo está licenciado sob a Licença Creative Commons CC-BY International. Com essa licença você pode compartilhar, adaptar, criar para qualquer fim, desde que atribua a autoria da obra.

\section{HISTÓRICO}

Recebido em 02/12/2017

Reapresentado em 30/11/2018

Aprovado em 03/04/2019 